\title{
Editorial: Global Undisciplined Benevolence
}

'The ardour of undisciplined benevolence seduces us into malignity and whenever our hearts are warmed and our objects great and excellent, intolerance is the sin that does most easily beset us'. Thus Coleridge, who added that those so seduced are apt to avert their eyes from the foulness of the road they tread, and necessarily tread, once they set their eyes on some distant ideal.

Although Coleridge was writing about the French Revolution, it cannot be said that intolerance regarding objects great and excellent has had any tendency to diminish since his day. Indeed the growth of communications has played a major role here. Think of Gladstone in the late 1870s whipping up hysteria in the towns and cities of England and Scotland over the 'Bulgarian horrors', during an election campaign he went on to win. But Gladstone on the stump is nothing compared to the reach and immediacy of the internet and social media, where vivid images and often febrile comment fly around in unedited form, untempered by background knowledge or reflection.

It cannot be said that all of this is bad, but not all is good either, especially where it leads to 'undisciplined' benevolence and consequent intolerance. Sometimes, indeed, the benevolent intolerance may be directed at the recipients of the benevolence, who are not always as grateful as their self-appointed benefactors think they should be.

Undisciplined benevolence is not just the province of the Mrs Jellebys of the world. A certain type of philosophical rationalism may actually be worse, that which identifies a problem, sees that the situation is in a certain sense 'irrational', and then concludes that reason 'requires' this or that, often involving interference in long-established customs and or the 'transfer' of resources from some people to others. Instant global communications may well encourage this type of mind-set, and the moralising that goes with it. And indeed, the irrational may be immoral. But saying that, and claiming the moral high ground in the matter, should make us the more aware of the potential foulness of the road our warmed hearts and inflamed reason may be urging us to tread, in pursuit of a future in truth at best perceived or understood through a glass darkly. 